Article

\title{
Pinus densiflora Sieb. et Zucc. Alleviates Lipogenesis and Oxidative Stress during Oleic Acid-Induced Steatosis in HepG2 Cells
}

\author{
Yu-Jin Hwang ${ }^{1,2}$, Hae-Ri Wi ${ }^{1}$, Haeng-Ran Kim ${ }^{1}$, Kye Won Park ${ }^{2}$ and Kyung-A Hwang ${ }^{1, *}$ \\ 1 Department of Agrofood Resources, National Academy of Agricultural Science, RDA, \\ Suwon 441-853, Korea; E-Mails: yujinh21@skku.edu (Y.-J.H.); hr226@naver.com (H.-R.W.); \\ kimhrr@korea.kr (H.-R.K.) \\ 2 Department of Food Science and Biotechnology, Sungkyunkwan University, Suwon 440-746, \\ Korea; E-Mail: kwpark@skku.edu \\ * Author to whom correspondence should be addressed; E-Mail: kah366@korea.kr; \\ Tel.: +82-31-299-0527; Fax: +82-31-299-0504.
}

Received: 5 June 2014; in revised form: 10 July 2014 / Accepted: 18 July 2014 /

Published: 23 July 2014

\begin{abstract}
Excess accumulation of lipids and oxidative stress in the liver contribute to nonalcoholic fatty liver disease (NAFLD). We hypothesized that Pinus densiflora Sieb. et Zucc. (PSZ) can protect against NAFLD by regulating lipid accumulation and oxidative stress in the liver. To investigate the effect of PSZ upon NAFLD, we used an established cellular model: HepG2 cells treated with oleic acid. Then, the extent of hepatic steatosis and oxidative stress was assessed and levels of inflammatory markers measured. Oleic acid-treated HepG2 cells, compared with controls, had greater lipid accumulation. PSZ decreased lipid accumulation by $63 \%$ in oleic acid-treated HepG2 cells. Additionally, PSZ decreased the target gene expression of lipogenesis such as sterol regulatory element binding protein-1c, fatty acid synthase, stearoyl-CoA desaturase-1, diacylglycerol $O$-acyltransferase-1, and acetyl-CoA carboxylase- 1 by $1.75,6.0,2.32,1.93$ and 1.81 fold, respectively. In addition, Oleic acid-treated HepG2 cells elicited extensive accumulation of tumor necrosis factor- $\alpha$ (TNF $\alpha$ ) by 4.53 fold, whereas PSZ-treated cells decreased the expression of TNF $\alpha$ mRNA by 1.76 fold. PSZ significantly inhibited oxidative stress induced by reactive oxygen species. These results suggest that PSZ has effects on steatosis in vitro and further studies are needed in vivo to verify the current observations.
\end{abstract}


Keywords: Pinus densiflora Sieb. et Zucc.; nonalcoholic fatty liver disease; hepatic lipid accumulation; oxidative stress

\section{Introduction}

The liver is the main organ for coordinating regulation of energy metabolism and lipid trafficking. Excess intake of lipids in the diet can lead to fatty liver, which can progress to nonalcoholic fatty liver disease (NAFLD) and non-alcoholic steatohepatitis (NASH). NAFLD is defined as hepatic macrovesicular steatosis upon consumption of alcohol of $<20 \mathrm{~g} /$ day. It is the most common liver disease in the USA [1-4]. NAFLD encompasses a wide spectrum of disorder and damage to the liver characterized by hepatic steatosis without significant consumption of alcohol and includes simple steatosis, inflammatory NASH, liver cirrhosis, and hepatocellular carcinoma [5].

Disorders of lipid metabolism in the liver are likely to play important parts in the initiation and development of NAFLD [6]. According to the "two hit" pathophysiological theory, the "first hit" is deposition of free fatty acids and triglyceride in hepatocytes (i.e., steatosis). The "second hit" is the progression of steatosis to NASH. This progression is associated with oxidative stress and the release of cytokines that can induce inflammation, fibrosis, or necrosis [7]. Further, the pro-inflammatory cytokine tumor necrosis factor (TNF)- $\alpha$ has a central role in the etiology of NASH due to its stimulation of hepatic lipogenesis and adipose lipolysis [8].

Oxidative stress is thought to be the main factor involved in the etiology of NASH. Oxidative stress results from an imbalance between pro-oxidant and antioxidant chemical species that leads to oxidative damage to cellular macromolecules [9]. The predominant pro-oxidant chemicals in fatty livers are singlet oxygen molecules, superoxide anions, hydrogen peroxide, and hydroxyl radicals: molecules referred to collectively as "reactive oxygen species" (ROS). Oxidation of fatty acids is an important source of ROS in fatty livers [10-13]. Thus, agents that can prevent or attenuate free fatty acid-induced lipogenesis and oxidative stress-induced damage represent promising therapeutic choices for NAFLD. Several agents are being tested for the treatment of NAFLD and, recently, the use of plants has emerged as a possible means to alleviate NAFLD. However, no medication has been approved for treating NAFLD [14-16].

Pinus densiflora Sieb. et Zucc. (PSZ) has been used as a folk remedy for rheumatism, hemorrhage, gastroenteritis, hypertension and asthma [17]. Recently, a broad spectrum of beneficial effects (antioxidative [18], anti-inflammatory [19,20], antitumor [21]) of PSZ has been reported. However, the anti-NAFLD effects of PSZ have not been identified. According to Kim [22], PSZ has several phytochemicals such as $\alpha$-pinene, $\beta$-pinene, camphene, quercetin, kaempferol, $\rho$-coumaric acid and choline. The biological or therapeutic activities of medicinal plants are closely related to their chemical compounds. For example, $\rho$-coumaric acid was found to modulate lipid metabolism in HepG2 cells via the AMPK activation pathway [23]. Quercetin effectively reversed NAFLD symptoms by decreased triacylglycerol accumulation, insulin resistance, inflammatory cytokine secretion and increased cellular antioxidants in OA induced hepatic steatosis in HepG2 cells [24]. In addition, due to NAFLD induced by choline-deficient, choline-rich PSZ would be help to improve NAFLD [25]. Often, the 
combination of several components is more effective than using any single constituent alone. Therefore, due to the synergistic effect of known components such as $\rho$-coumaric acid, choline and quercetin, PSZ would be useful material for the anti-NAFLD.

In the present study, we investigated the beneficial effects of PSZ (a candidate for the treatment of NAFLD) on the inhibition of fat accumulation and oxidative stress in the liver.

\section{Experimental Section}

\subsection{Samples, Antibodies, and Reagents}

Ethanol (70\%) extracts of PSZ was purchased from the Plant Extract Bank (Je-ju, Korea). Dulbecco's modified Eagle's medium (DMEM), fetal bovine serum (FBS), and penicillin-streptomycin were obtained from Gibco (Carlsbad, CA, USA). Antibodies against sterol regulatory element binding protein-1c (SREBP-1c), liver X receptor- $\alpha$ (LXR $\alpha)$, 5' AMP-activated protein kinase (AMPK) and $\beta$-actin were purchased from Abcam (Cambridge, MA, USA). Oil-red-O, oleic acid (OA) was obtained from Sigma-Aldrich (Saint Louis, MO, USA). Nile Red, boron-dipyrromethene (BODIPY 493/503) and dichlorofluorescein diacetate (DCF-DA) were purchased from Invitrogen (Carlsbad, CA, USA). CellTiter Glo was obtained from Promega (Madison WI, USA). All other chemicals were purchased from Sigma-Aldrich unless specified otherwise.

\subsection{OA/BSA Complex Solution Preparation}

OA/BSA complex solution was prepared by a slight modification of previously described methods [26]. One hundred mM OA stock solution was prepared in $0.1 \mathrm{~N} \mathrm{NaOH}$ by heating at $70{ }^{\circ} \mathrm{C}$ in a shaking water bath. In an adjacent water bath at $55{ }^{\circ} \mathrm{C}$, a $10 \%(\mathrm{w} / \mathrm{v})$ FFA-free BSA solution was prepared in $\mathrm{H}_{2} \mathrm{O}$. Twenty mM OA containing $10 \%$ BSA was diluted in the culture medium to obtain the desired final concentrations. The OA/BSA complex solution was sterile-filtered through a $0.45 \mu \mathrm{m}$ pore membrane filter and stored at $-20{ }^{\circ} \mathrm{C}$.

\subsection{Cell Culture}

The human hepatocellular carcinoma cell line HepG2 was obtained from Korean Cell Line Bank (Seoul, Korea). HepG2 cells were routinely cultured in DMEM (Gibco) supplemented with 10\% FBS and $1 \%$ penicillin-streptomycin in an incubator under an atmosphere of $5 \% \mathrm{CO} 2$ at $37{ }^{\circ} \mathrm{C}$. To accumulate fatty acids, HepG2 cells were exposed to OA at a final concentration of $2 \mathrm{mM}$ for $24 \mathrm{~h}$.

\subsection{Cytotoxicity}

HepG2 cells $\left(1 \times 10^{5}\right.$ cells/well $)$ in 24 -well plates were treated with PSZ. PSZ ethanol extract in dimethyl sulfoxide (DMSO) was diluted in phosphate-buffered saline (PBS) to obtain final concentrations of 100, 200, and $500 \mu \mathrm{g} / \mathrm{mL}$. Cells were treated with extract samples for $24 \mathrm{~h}$, and cell viability measured with CellTiter Glo ${ }^{\circledR}$ (Promega). Viability is presented as the percentage of live cells in each well. 


\subsection{Staining Using Oil-red-O, BODIPY, and Nile Red}

HepG2 cells $\left(2 \times 10^{5}\right.$ cells $\left./ \mathrm{mL}\right)$ were treated with PSZ $(100 \mu \mathrm{g} / \mathrm{mL})$ and OA $(2 \mathrm{mM})$ for $24 \mathrm{~h}$. Resveratrol $(50 \mu \mathrm{M})$ as the one of effective natural compounds is used as the positive control. After incubation, cells were fixed with 4\% paraformaldehyde and stained with a freshly prepared working solution of Oil-red-O for $20 \mathrm{~min}$ at room temperature. After several washings, cells were observed under a microscope (Nikon, Tokyo, Japan).

To quantify Oil-red-O content, isopropanol was added to each sample, which was shaken at room temperature for $5 \mathrm{~min}$, and the optical density of the isopropanol-extracted sample read using a spectrophotometer at $510 \mathrm{~nm}$.

\subsection{Real-Time Reverse Transcription-Polymerase Chain Reaction (RT-PCR) Analyses}

RT-PCR was undertaken to determine the expression of lipids using a Rotor-Gene Q Real-time Thermal Cycler (Qiagen, Stanford, VA, USA) according to manufacturer instructions. HepG2 cells were treated with PSZ $(100 \mu \mathrm{g} / \mathrm{mL})$ and OA $(2 \mathrm{mM})$ for $24 \mathrm{~h}$. After incubation, cDNA was synthesized from the total RNA isolated from cells. The PCR was carried out using 2X SYBR Green mix (Qiagen). All results were normalized to expression of glyceraldehydes-3-phosphate dehydrogenase. Primer sequences are shown in Table 1.

Table 1. Gene-specific primers used for real-time RT-PCR.

\begin{tabular}{|c|c|c|}
\hline Gene & Forward & Reverse \\
\hline SREBP-1 & 5'-GCGGAGCCATGGATTGCAC-3' & 5'-TCTTCCTTGATACCAGGCCC-3' \\
\hline FAS & 5'-AGCTGCCAGAGTCGGAGAAC-3' & 5'-TGTAGCCCACGAGTGTCTCG-3' \\
\hline SCD1 & 5'-CCAACACAATGGCATTCCAG-3' & 5'-GGTGGTCACGAGCCCATTC-3' \\
\hline $\operatorname{PPAR} \gamma$ & 5'-GAACAGATCCAGTGGTTGCAG-3' & 5'-GGCATTATGAGACATCCCCAC-3' \\
\hline DGAT1 & 5'-GGCATCCTGAACTGGTGTGTG-3' & 5'-GAGCTTGAGGAAGAGGATGGTG-3' \\
\hline $\mathrm{ACC} 1$ & 5'-GAGGGCTAGGTCTTTCTGGAAG-3' & 5'-CCACAGTGAAATCTCGTTGAGA-3' \\
\hline $\operatorname{PPAR} \alpha$ & 5'-TCCGACTCCGTCTTCTTGAT-3' & 5'-GCCTAAGGAAACCGTTCTGTG-3' \\
\hline CPT1 & 5'-TGAGCGACTGGTGGGAGGAG-3' & 5'-GAGCCAGACCTTGAAGTAGCG-3' \\
\hline $\mathrm{ACOX}$ & 5'-TCCTGCCCACCTTGCTTCAC-3' & 5'-TTGGGGCCGATGTCACCAAC-3' \\
\hline $\mathrm{ACC} 2$ & 5'-GCCAGAAGCCCCCAAGAAAC-3' & 5'-CGACATGCTCGGCCTCATAG-3' \\
\hline $\mathrm{TNF} \alpha$ & 5'-CAGCCTCTTCTCCTTCCTGAT-3' & 5'-GCCAGAGGGCTGATTAGAGA-3' \\
\hline
\end{tabular}

\subsection{Western Blot Analyses}

HepG2 cells were treated with PSZ $(100 \mu \mathrm{g} / \mathrm{mL})$ and OA $(2 \mathrm{mM})$ for $24 \mathrm{~h}$. After incubation, cells were lysed with lysis buffer $(150 \mathrm{mM}$ sodium chloride, $1 \%$ Triton $\mathrm{X}-100,1 \%$ sodium deoxycholate, $0.1 \%$ sodium dodecyl sulfate, $50 \mathrm{mM}$ Tris- $\mathrm{HCl}, \mathrm{pH} 7.5$, and $2 \mathrm{mM}$ ethylenediamine tetra-acetic acid) on ice for $30 \mathrm{~min}$. After centrifugation $\left(12,000 \times \mathrm{g}\right.$, for $15 \mathrm{~min}$ at $\left.4{ }^{\circ} \mathrm{C}\right)$, the supernatant was collected, and protein concentrations determined using a bicinchoninic acid assay (GenDEPOT; Barker, TX, USA). Equal amounts (10 $\mu \mathrm{g})$ of cell extracts were separated by sodium dodecyl sulfate-polyacrylamide gel electrophoresis and transferred to polyvinylidene difluoride membranes (Bio-Rad, Hercules, CA, 
USA). Membranes were blotted with antibody, and detection undertaken with an enhanced chemiluminescence system (Pierce, Rockford, IL, USA) according to manufacturer instructions.

\subsection{Cytokine Determinations}

HepG2 cells were treated with PSZ $(100 \mu \mathrm{g} / \mathrm{mL})$ and OA $(2 \mathrm{mM})$ for $24 \mathrm{~h}$. After incubation, the supernatants were collected. The TNF $\alpha$ levels in the culture medium were determined by a Duo Set mouse TNFa ELISA kit according to the manufacturer's protocols (R\&D Systems, Minneapolis, $\mathrm{MN}, \mathrm{USA})$.

\subsection{Flow Cytometric Analyses of the Scavenging Activity of Intracellular ROS}

HepG2 cells were treated with PSZ $(100 \mu \mathrm{g} / \mathrm{mL})$ and OA $(2 \mathrm{mM})$ for $24 \mathrm{~h}$. After incubation, cells were stained with dichlorofluorescein diacetate (DCF-DA) according to manufacturer instructions. Stained cells were subjected to flow cytometric analyses using FACSCalibur (Becton Dickinson Biosciences, San Jose, CA, USA).

\subsection{Statistical Analyses}

Statistical analyses were undertaken with SPSS v12.0 (SPSS, Chicago, IL, USA). Data are the mean \pm SEM from three independent experiments unless stated otherwise. Statistical analyses were done using the Student's $t$-test and $p<0.05$ was considered significant.

\section{Results}

\subsection{Cytotoxic Effects of PSZ on HepG2 Cells}

Cytotoxic effects of PSZ on HepG2 cells were determined by exposing them to PSZ (100, 200, and $500 \mu \mathrm{g} / \mathrm{mL}$ ) for $24 \mathrm{~h}$. We estimated the influence on cell survival according to the following criteria [27,28]: Cell viability values greater than 90\% were considered unaffected by tested compounds, $80 \%-90 \%$ was modestly affected, and values less than $80 \%$ were considered affected by the cytotoxic effects of the compounds. PSZ suppressed the proliferation of HepG2 cells in a dose-dependent manner (Figure 1A). In groups treated with 200 and $500 \mu \mathrm{g} / \mathrm{mL} \mathrm{PSZ}$, the viability of HepG2 cells after exposure was $82 \%$ and $73 \%$, respectively. HepG2 cells were treated with $0-2 \mathrm{mM}$ $\mathrm{OA}$ for $24 \mathrm{~h}$ to induce hepatic steatosis, yet this action did not result in cytotoxicity (Figure 1B). Therefore, according to criteria, $100 \mu \mathrm{g} / \mathrm{mL}$ PSZ and $2 \mathrm{mM} \mathrm{OA}$ were used to induce fatty liver. 
Figure 1. Cell viability effect of Pinus densiflora Sieb. et Zucc. (PSZ) in HepG2 cells. (A) HepG2 cells were treated with PSZ (100, 200 and $500 \mu \mathrm{g} / \mathrm{mL})$ and (B) HepG2 cells were treated with oleic acid $(\mathrm{OA} ; 0.5,1$ and $2 \mathrm{mM})$. After treatment for $24 \mathrm{~h}$, cell viability was quantified by measuring intracellular levels of ATP. Bars represent the mean \pm SEM of three experiments done in triplicate.

(A)

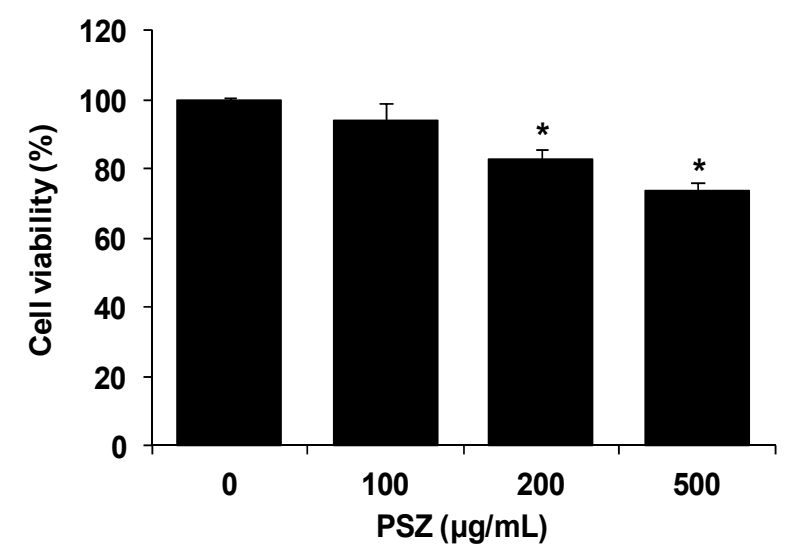

(B)

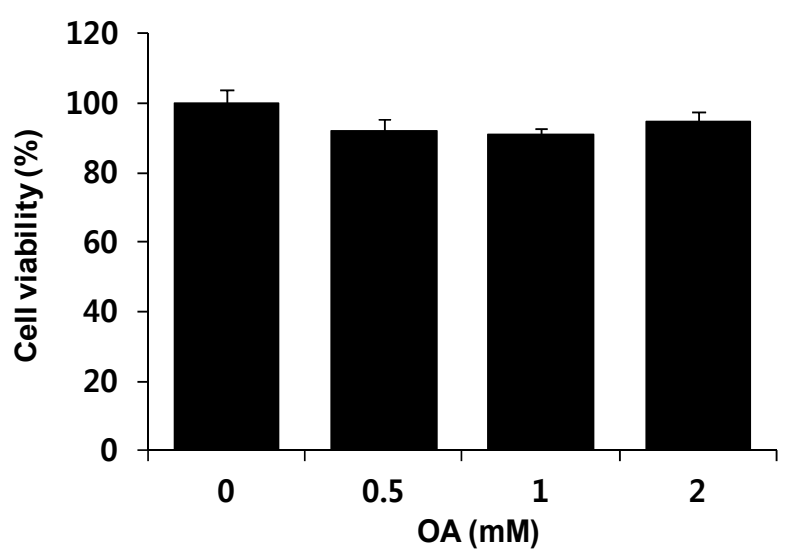

\subsection{PSZ Reduces OA-Induced Steatosis in HepG2 Cells}

Cultured HepG2 cells were exposed to OA and lipid accumulation detected by staining using Oil-red-O, BODIPY and Nile Red after 24 h. Significant differences between control groups and OA groups were noted (Figure 2A). HepG2 cells in the control group did not suffer steatosis, whereas cells in the OA group had severe steatosis. A greatly reduced number of lipid droplets was noted in the PSZ group compared with the OA group. Lipid accumulated in OA-treated cells and PSZ significantly decreased lipid accumulation by $63 \%$ compared with the OA group. Resveratrol reduced TG content by $54 \%$ compared with the OA group (Figure $2 \mathrm{~B}$ ).

We measured the lipid accumulation by various methods (Oil-red-O, BODIPY and Nile Red). The reason is to confirm that it is not just an Oil-red-O specific effect by using at least one other staining reagent. Whereas Oil-red-O was used a total lipid staining, the BODIPY and Nile Red fluorescence can be used to distinguish neutral lipids from phospholipids or other amphipathic lipids $[29,30]$. That is why the staining patterns of our result are different. The BODIPY and Nile Red dye reveals intensely staining foam cells and lipid droplet clusters, as well as a less intense widespread staining of almost the entire cell. 
Figure 2. Effects of Pinus densiflora Sieb. et Zucc. (PSZ) on steatosis in HepG2 cells stimulated with oleic acid (OA). (A) HepG2 cells were treated with $100 \mu \mathrm{g} / \mathrm{mL}$ PSZ. After treatment for $24 \mathrm{~h}$, lipid accumulation was measured by staining with Oil-red-O, BODIPY, and Nile Red. (B) Lipid accumulation was quantified by measuring the extracted dye at $510 \mathrm{~nm}$. Results are the mean \pm SEM from three independent experiments. ${ }^{*} p<0.05$ compared with the OA group. DMEM, control group; OA, oleic acid-treated group; PSZ, $\mathrm{OA}+$ Pinus densiflora Sieb. et Zucc.-treated group; RV, OA + resveratrol-treated group.

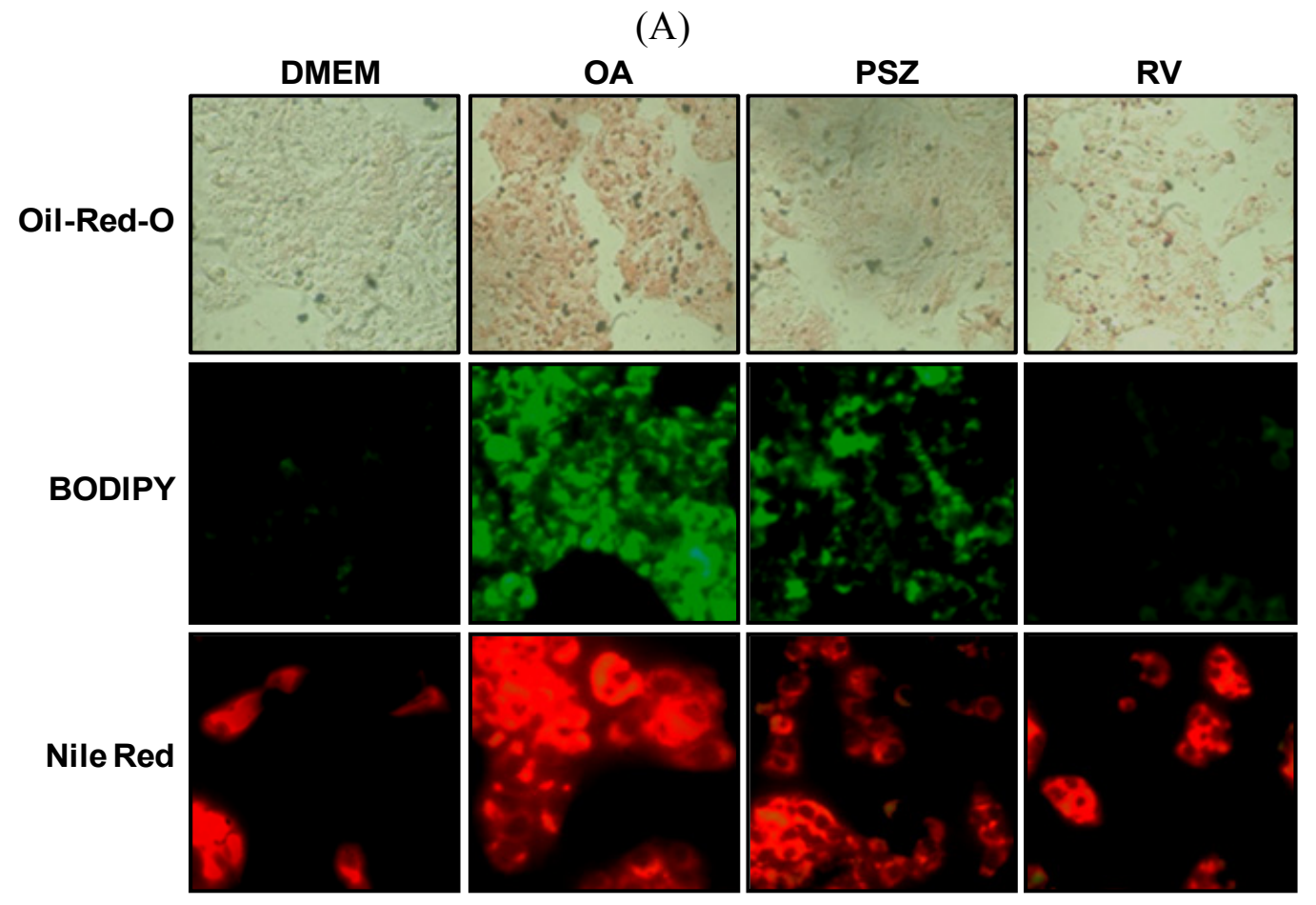

(B)

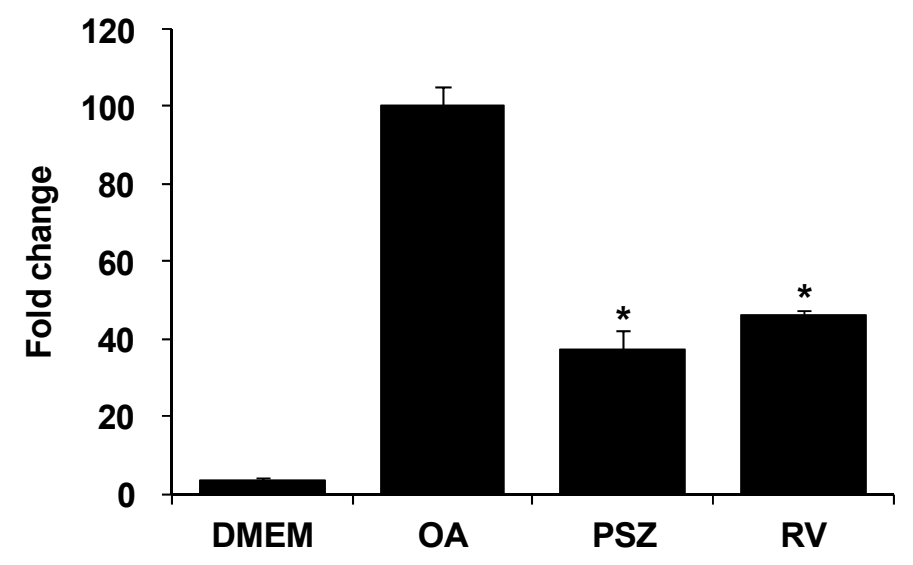




\subsection{PSZ Attenuates Hepatic Steatosis via Inhibition of Expression of Lipogenic Genes}

We examined the expression of genes that regulate lipid metabolism to better define how PSZ inhibits hepatic steatosis. Expression of the lipogenic genes SREBP-1c, diacylglycerol-Oacyltransferase 1 (DGAT1), peroxisome proliferator-activated receptor gamma (PPAR $\gamma$ ), stearoyl-CoA desaturase 1 (SCD1), fatty acid synthase (FAS), and acetyl-CoA carboxylase (ACC1) was upregulated significantly in OA-treated HepG2 cells. PSZ decreased the mRNA expression of lipogenic genes (Figure 3). In contrast, PSZ did not increase the expression of lipolytic genes such as PPAR $\alpha$, acyl-CoA oxidase (ACOX) and ACC2 except carnitine palmitoyltransferase I (CPT1) (Figure 4). We confirmed that resveratrol affected the lipolytic pathway rather than inhibiting the lipogenic pathway. Collectively, these data suggested that PSZ suppressed hepatic lipogenesis and CPT1-mediated lipolysis.

Figure 3. Effects of Pinus densiflora Sieb. et Zucc. (PSZ) on expression of lipogenesis genes in HepG2 cells stimulated with oleic acid (OA). HepG2 cells were treated with $100 \mu \mathrm{g} / \mathrm{mL}$ PSZ and OA. After treatment for $24 \mathrm{~h}$, RNA was isolated and reverse-transcribed for RT-PCR analyses using the primers described in Table 1. Results are the mean \pm SEM from three independent experiments. ${ }^{*} p<0.05$ compared with the OA group. DMEM, control group; OA, oleic acid-treated group; PSZ, OA + Pinus densiflora Sieb. et Zucc.-treated group; RV, OA + resveratrol-treated group.
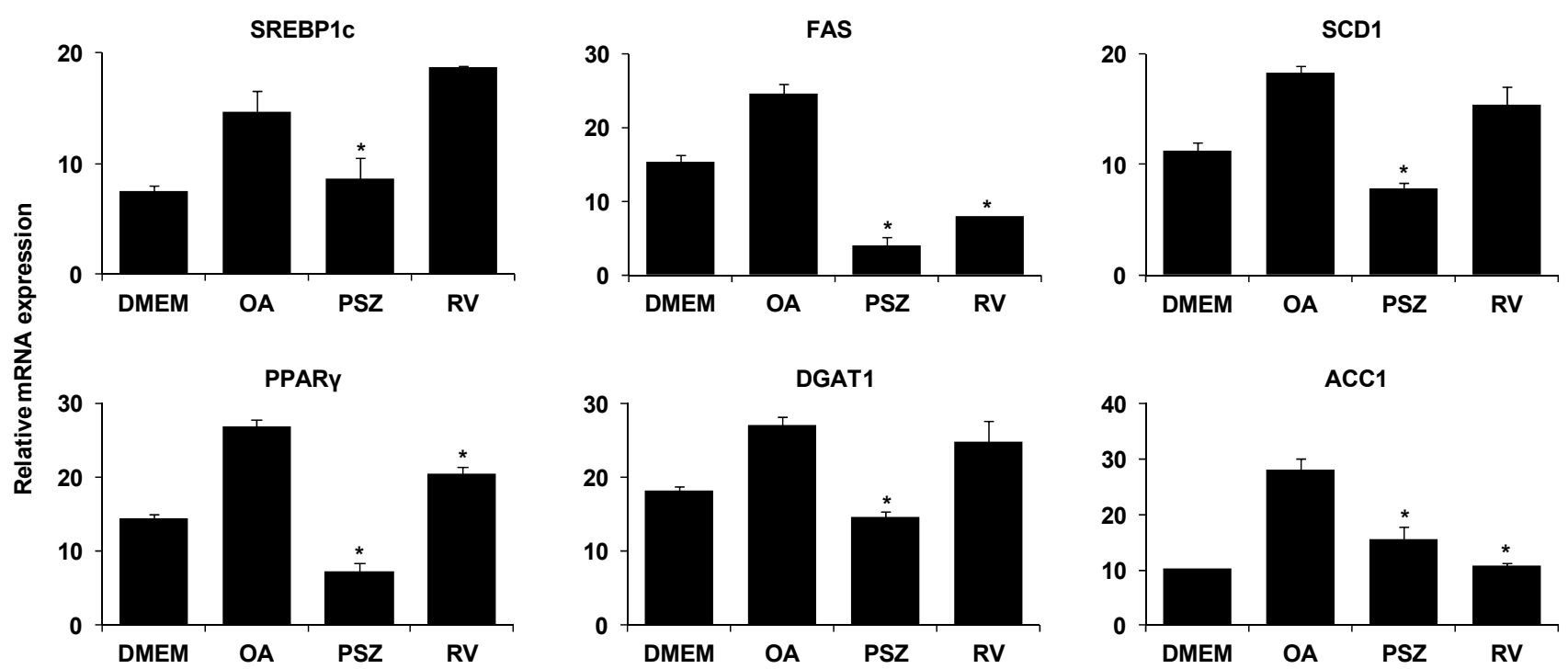

\subsection{PSZ Attenuates the Transcription Factors for Lipogenic Genes}

SREBP-1c is a transcription factor that regulates the expression of lipogenic genes, including ACCs and FAS. SREBP-1c is activated by LXR (a nuclear receptor that regulates the metabolism of cholesterol and fatty acids) [31]. AMPK is a sensor of energy homeostasis in cells. If AMPK is activated, it "switches on" catabolic pathways (e.g., fatty-acid oxidation and glycolysis) and "switches off” adenosine triphosphate-consuming pathways (e.g., lipogenesis) [9]. 
Figure 4. Effects of Pinus densiflora Sieb. et Zucc. (PSZ) on expression of hepatic lipolysis genesin HepG2 cells stimulated with oleic acid (OA). HepG2 cells were treated with $100 \mu \mathrm{g} / \mathrm{mL}$ PSZand OA. After treatment for $24 \mathrm{~h}$, RNA was isolated and reverse-transcribed for RT-PCR analyses using the primers described in Table 1. Results are the mean \pm SEM from three independent experiments. $* p<0.05$ compared with the OA group. DMEM, control group; OA, oleic acid-treated group; PSZ, OA + Pinus densiflora Sieb. et Zucc.-treated group treated group; RV, OA + resveratrol-treated group.

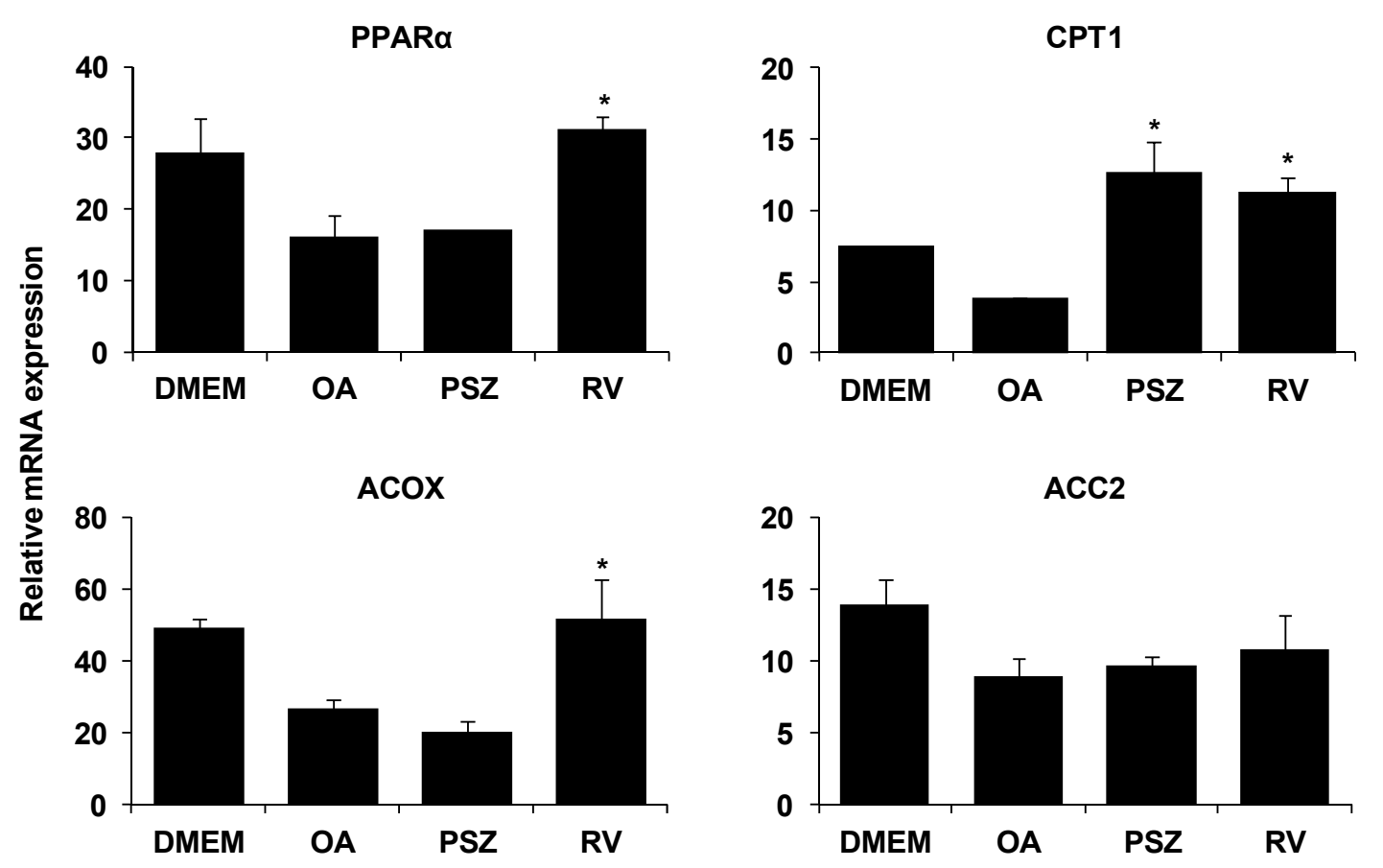

Figure 5. Effects of Pinus densiflora Sieb. et Zucc. (PSZ) on expression of the transcription factor for lipogenic genes in HepG2 cells stimulated with oleic acid (OA). HepG2 cells were treated with $100 \mu \mathrm{g} / \mathrm{mL}$ PSZ and OA. After treatment for $24 \mathrm{~h}$, whole-cell lysates were subjected to western blot analyses for anti-SREBP-1c, LXR, and AMPK antibodies. $\beta$-Actin was used as the internal control. Results are the mean \pm SEM from three independent experiments. DMEM, control group; OA, oleic acid-treated group; PSZ, $\mathrm{OA}+$ Pinus densiflora Sieb. et Zucc.-treated group; RV, OA + resveratrol-treated group.
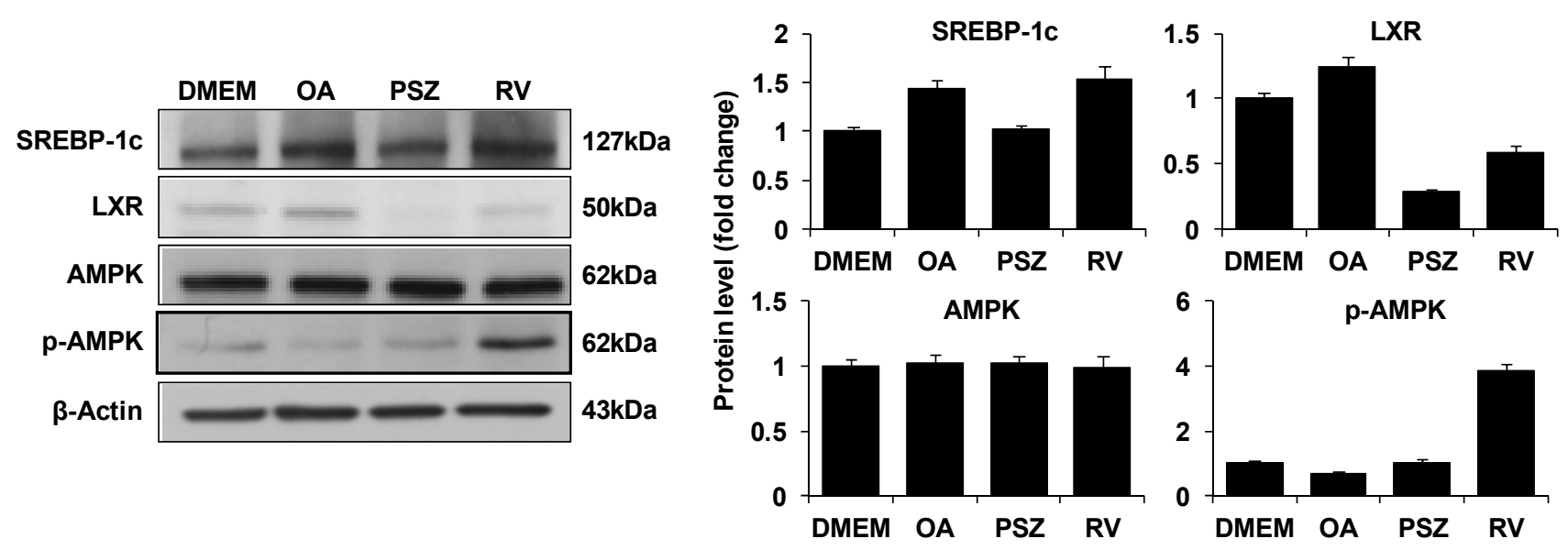
To understand the mechanisms involved in the pathogenesis of NAFLD, we investigated expression of transcription factors by western blotting. The level of immature SREBP-1c increased in the OA-treated group of HepG2 cells (Figure 5). However, immature SREBP-1c expression decreased in cells treated with PSZ compared with that seen in the OA group. Similar results were obtained for LXR expression. Expression of AMPK protein was not significantly different in the PSZ group compared with that in the OA group. In addition, we found that the expression pattern of p-AMPK did not change in the PSZ-treated group but p-AMPK was increased in the RV group. Taken together, these data suggested that PSZ suppressed hepatic lipogenesis by regulating expression of LXR and SREBP-1c.

\subsection{PSZ Decreases Hepatic Inflammation by Attenuating TNFa Expression}

Accumulation of FFA results in lysosomal permeabilization and then release of a lysosomal protease, namely ctsb, into the cytosol activates a feature of TNF $\alpha$ signaling cascades [32]. Hepatic steatosis is associated with increased expression of TNF $\alpha$, which stimulates lipogenesis and lipolysis as well as inducing hepatic dysfunction [33]. We confirmed TNF $\alpha$ production by the enzyme-linked immunosorbent assay (ELISA). TNF $\alpha$ content was greater in the OA group and lower in the OA + PSZ group (Figure 6A). Expression of TNF- $\alpha$ mRNA was six-fold greater in the OA group and was decreased by $43 \%$ in the OA + PSZ (Figure $6 \mathrm{~B}$ ).

Figure 6. Effects of Pinus densiflora Sieb. et Zucc. (PSZ) on TNFa production (A) and mRNA expression (B) in oleic acid (OA)-induced HepG2 cells. (A) HepG2 cells were treated with $100 \mu \mathrm{g} / \mathrm{mL}$ PSZ. After treatment for $24 \mathrm{~h}$, the supernatant was collected. TNF $\alpha$ production was quantified by ELISA. (B) HepG2 cells were treated with $100 \mu \mathrm{g} / \mathrm{mL}$ PSZ. After treatment for $24 \mathrm{~h}$, RNA was isolated and reverse-transcribed for RT-PCR analyses using the primers described in Table 1. Results are the mean \pm SEM from three independent experiments. ${ }^{*} p<0.05$ compared with the OA group. DMEM, control group; OA, oleic acid-treated group; PSZ, OA + Pinus densiflora Sieb. et Zucc.-treated group; $\mathrm{RV}, \mathrm{OA}+$ resveratrol treated group.

(A)

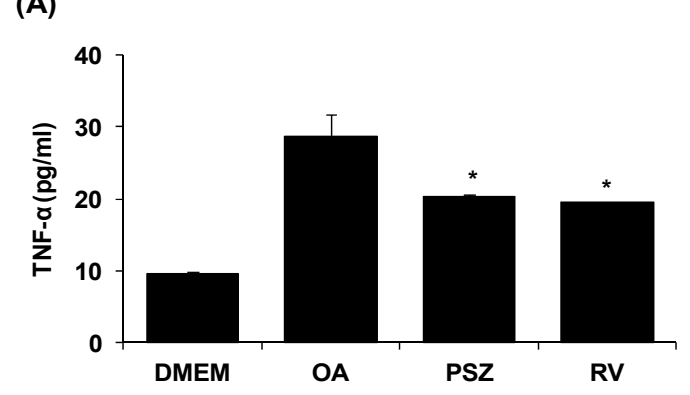

(B)

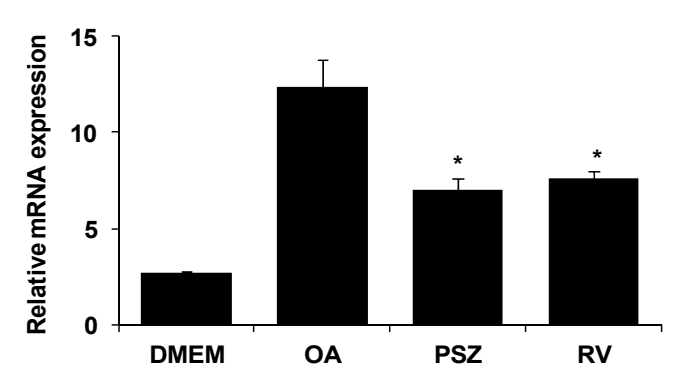




\subsection{PSZ Inhibits ROS Production}

NAFLD and oxidative stress are positively correlated, and the production of ROS is enhanced by excess fat accumulation [34]. Intake of large amounts of glucose and free fatty acids induces acetyl-CoA production and excess NADH. Accumulation of excess NADH causes a generation of ROS [35]. In addition, the increased TNF $\alpha$ by OA induce the expression of NOX3 protein and subsequently the induced NOX3 increase the ROS production [36]. The accumulated ROS generates a lipid peroxidation result in subsequent damage to hepatic membranes, proteins and DNA [37]. Therefore, we evaluated the inhibition of ROS production by PSZ on OA-induced HepG2 cell. OA treatment significantly increased ROS formation in HepG2 cells as determined by DCF-DA fluorescence (Figure 7). However, treatment with PSZ and resveratrol blocked OA-induced ROS generation.

Figure 7. Effects of Pinus densiflora Sieb. et Zucc. (PSZ) on ROS-scavenging activity in oleic acid (OA)-induced HepG2 cells. HepG2 cells were treated with $100 \mu \mathrm{g} / \mathrm{mL}$ PSZ. After treatment for $24 \mathrm{~h}$, cells were harvested and stained with DCF-DA. Results are the mean \pm SEM from three independent experiments. ${ }^{*} p<0.05$ compared with the OA group. DMEM, control group; OA, oleic acid-treated group; PSZ, OA + Pinus densiflora Sieb. et Zucc.-treated group; RV, OA + resveratrol-treated group.
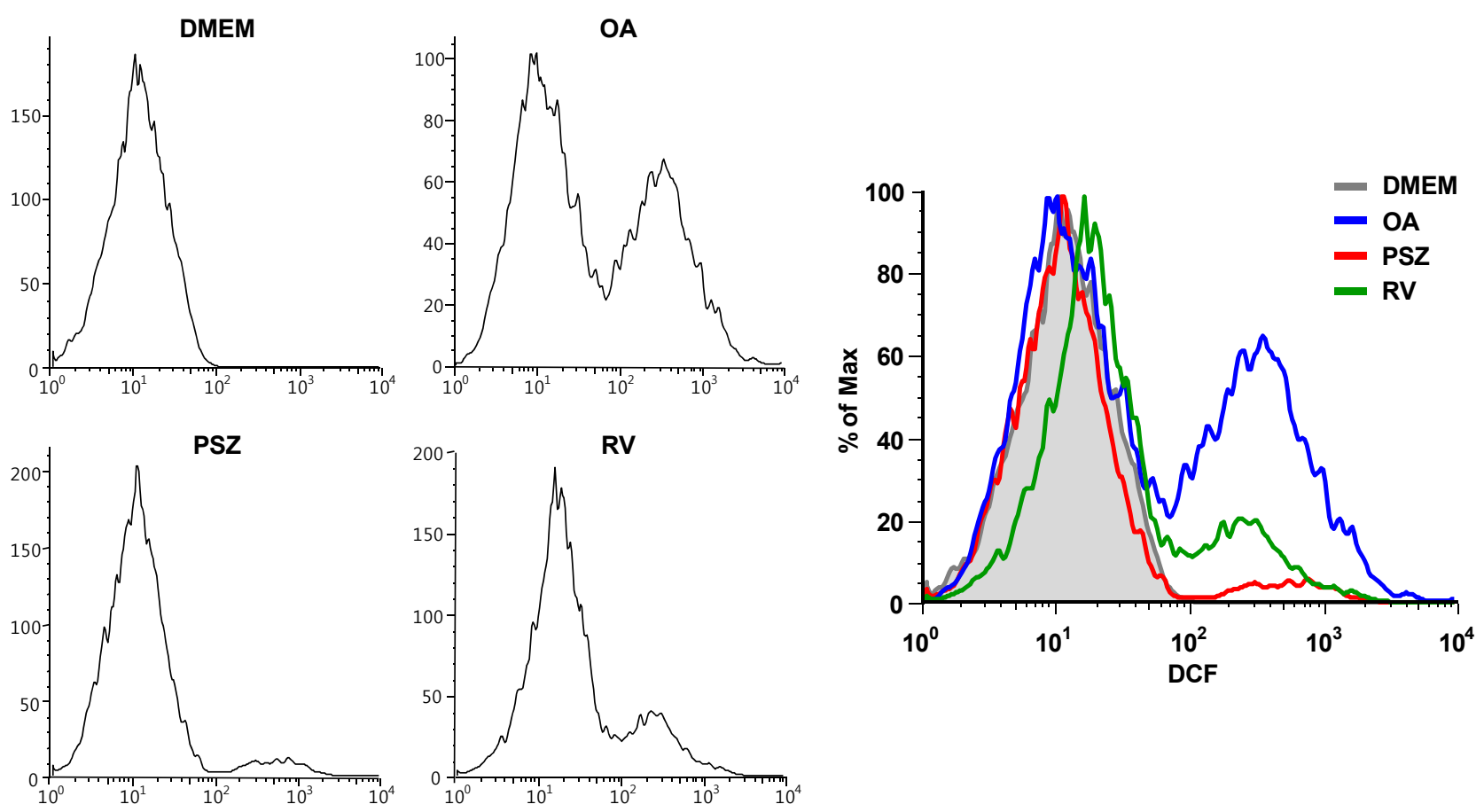

\section{Discussion}

NAFLD is a clinicopathological change characterized by accumulation of triglycerides in hepatocytes. NAFLD is one of the most frequent causes of abnormal liver function tests [38]. Recently, the incidence of NAFLD has increased markedly, accompanying the increased prevalence of obesity and type- 2 diabetes mellitus. More than $10 \%$ of patients with NAFLD progress to NASH, which is 
characterized by infiltration of inflammatory cells in the liver and the ballooning of hepatocytes. Liver cirrhosis and hepatocellular carcinoma eventually occur in some patients with NASH [39].

Several agents have been developed to improve NAFLD. In addition, due to problems related to conventional treatment methods and the side effects of these agents, research has concentrated on new treatments, such as using natural products, to develop treatments for NAFLD and NASH [40,41]. Many plants with different pharmacological features are known to contain chemical compounds that may be suitable for the treatment or prevention of NAFLD [42]. Several plants have been examined to identify natural products that could prevent hepatic lipogenesis and be new effective compounds in the treatment of NAFLD [43,44].

We investigated if PSZ protects against NAFLD by decreasing lipogenesis. Our results also demonstrated that PSZ decreases the oxidative stress and inflammatory responses known to contribute to the development of NAFLD. In addition, PSZ inhibited the expression of TNF $\alpha$ protein and mRNA that are otherwise increased by NAFLD. Taken together, these results suggest that PSZ alleviates NAFLD by inhibiting hepatic lipogenesis by regulating expression of SREBP-1c and LXR as well as decreasing ROS production. Based on the results of the present study, the mechanism by which PSZ extract inhibits NAFLD in HepG2 cells is summarized in Figure 8.

Figure 8. Proposed model for the inhibition of steatosis by Pinus densiflora Sieb. et Zucc. (PSZ) extracts in HepG2 cells. PSZ decreases TNF production, hepatic lipogenesis and oxidative stress, resulting in the improvement of hepatic steatosis.

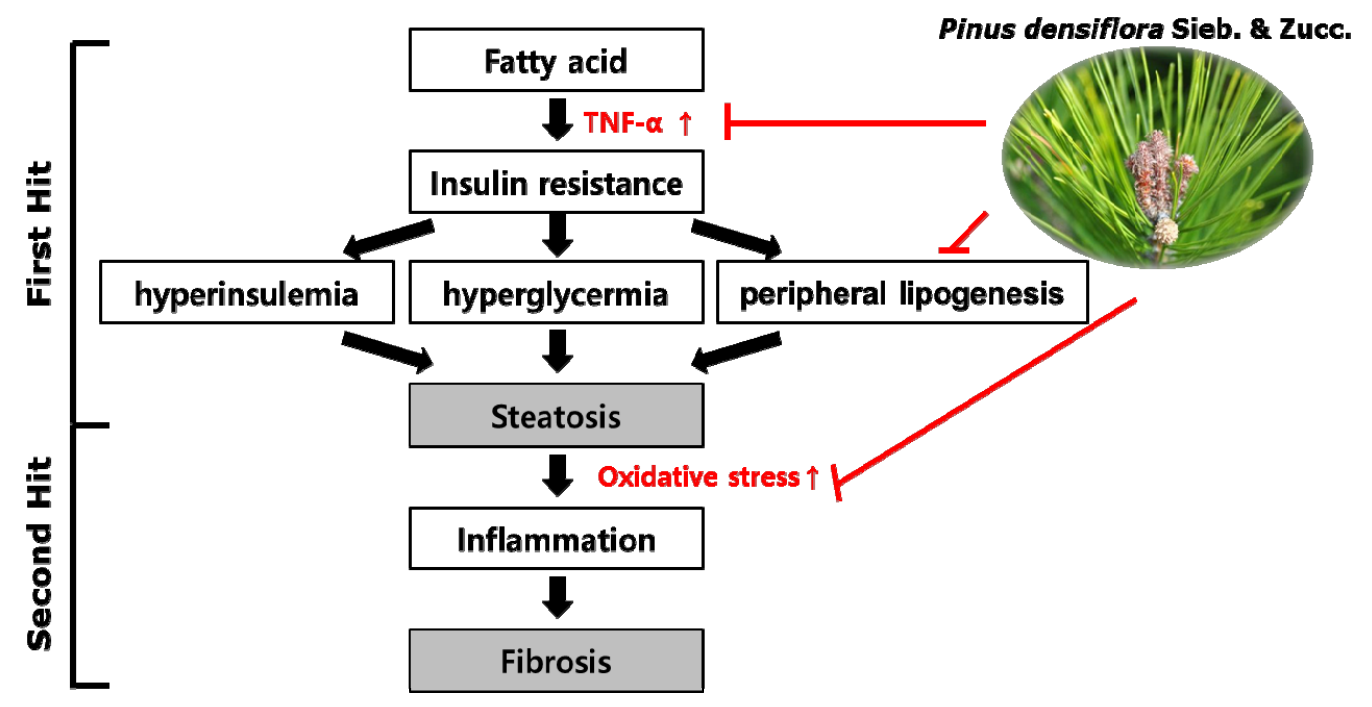

This is the first study to demonstrate PSZ-mediated reductions in hepatic lipid accumulation. In OA-treated HepG2 cells, expression of lipogenic genes such as SREBP-1c, FAS and DGAT1 was upregulated. PSZ suppressed expression of these lipogenic genes, whereas it did not affect expression of lipolytic genes apart from CPT1. Lipid accumulation in liver may be caused by enhanced de novo lipogenesis, activation of lipid uptake, and lowering of lipid catabolism [45]. FAS, SCD-1 and DGAT1 are key enzymes in de novo fatty acid and TG synthesis in mammals. SREBP-1 is well known as the transcription factor regulating the gene expression of these lipogenic enzymes in the liver. FAS, SCD-1 and DGAT1 are known to be changed by SREBP-1 [46]. Our results indicate that the effect of PSZ on OA-induced hepatic lipogenesis in HepG2 cells is associated with decreased expression of SREBP-1 
and its downstream lipogenic genes such as FAS, SCD-1 and DGAT1. Taken together, the decrease of FAS, SCD-1 and DGAT1 by regulation of SREBP-1 would be helpful to the inhibition of lipid accumulation by inhibiting the TG synthesis.

AMPK is involved in regulating hepatic lipogenesis and may be a therapeutic target for treating fatty liver disease [47]. It is known that SREBP-1c is negatively regulated by AMPK [48]. In the present study, it was found that OA significantly increased SREBP-1c and FAS expression in parallel with AMPK phosphorylation was decreased, indicating that the negative feedback regulation of SREBP-1c via AMPK in OA-induced conditions. PSZ also did not rescue the AMPK expression and the expression of AMPK target genes such as PPAR $\alpha$, ACOX, ACC2 except CPT1. In case of an increase in the CPT1 expression, PSZ causes inhibition of $\mathrm{ACC} 1$, which reduce the production of malonyl-CoA, an inhibitor of CPT1 [49,50]. Thus, ACC1 inhibition by PSZ appears to be important in regulating CPT1 activity. The results suggest that PSZ may also reduce lipid levels via promotion of hepatic fatty acid oxidation.

Various studies have shown that elevated TNF $\alpha$ plays a key role in the pathogenesis and disease progression of NAFLD [51,52]. According to Cui et al. [53], they reported that treatment of HepG2 cells with FFA resulted in increased the expression of TNF- $\alpha$ mRNA. In present study, we also confirm that OA treatment significantly increased TNF- $\alpha$ production from HepG2 cell. A key question is whether increased TNF- $\alpha$ in NAFLD is from hepatocytes or other inflammatory cells [54]. However, there should be further study to clarify whether the FFA-induced steatosis promotes expression of TNF $\alpha$ mRNA.

The present study showed that PSZ decreased TNF $\alpha$ production that was associated with increases in hepatic lipid content. In addition, NAFLD is also associated with oxidative stress and inflammatory responses that exacerbate liver injury [55]. Extracts from pine trees have been suggested to protect against oxidative stress [18]. Kwak et al. [21] reported that the free radical scavenging activity of pine needles ethanol extract appeared to be similar to that of $\alpha$-tocopherol; the $\mathrm{EC}_{50}$ assessed for both pine needles ethanol extract and $\alpha$-tocopherol was $95.12 \mu \mathrm{g} / \mathrm{mL}$ and $95.54 \mu \mathrm{g} / \mathrm{mL}$, respectively. This result indicates that PSZ is very powerful antioxidant material. Also, according to Jung et al. [56], PSZ methanol extract and its various fractions have significant effects on scavenging free radicals. Our results showed that OA-treated HepG2 cells had elevated levels of ROS, whereas PSZ restored ROS to normal levels. This result is in agreement with their studies. However, additional in vivo work is needed to identify the exact antioxidant defense mechanism of PSZ extract.

\section{Conclusions}

PSZ effectively reversed NAFLD symptoms by decreasing lipid accumulation, secretion of inflammatory cytokines and oxidative stress in HepG2 cells. Hence, more experimental and clinical studies are needed to understand how PSZ prevents NAFLD.

\section{Acknowledgements}

This study was carried out with the support of the Research Program for Agricultural Science \& Technology Development (project number PJ00846201, National Academy of Agricultural Science, Rural Development Administration, Republic of Korea). 


\section{Author Contributions}

Hwang, K.-A. conceived the study and designed the experiments. Hwang, Y.-J. and Wi, H.-R. performed most of the experiments. All authors including Kim, H.-R. and Park, K.W. analyzed the data and discussed the results. Hwang, K.-A. supervised the project and wrote the manuscript with the help of Hwang, Y.-J.; Wi, H.-R.; Kim, H.-R. and Park, K.W.

\section{Conflicts of Interest}

The authors declare no conflict of interest.

\section{References}

1. Clark, J.M.; Brancati, F.L.; Diehl, A.M. Nonalcoholic fatty liver disease. Gastroenterology 2002, 122, 1649-1657.

2. Browning, J.D.; Szczepaniak, L.S.; Dobbins, R.; Nuremberg, P.; Horton, J.D.; Cohen, J.C.; Grundy, S.M.; Hobbs, H.H. Prevalence of hepatic steatosis in an urban population in the United States: Impact of ethnicity. Hepatology 2004, 40, 1387-1395.

3. Pais, R.; Ratziu, V. Epidemiology and natural history of nonalcoholic fatty liver disease. Rev. Prat. 2012, 62, 1416-1421.

4. Tolman, K.G.; Dalpiaz, A.S. Treatment of non-alcoholic fatty liver disease. Ther. Clin. Risk Manag. 2007, 3, 1153-1163.

5. Contos, M.J.; Choudhury, J.; Mills, A.S.; Sanyal, A.J. The histologic spectrum of nonalcoholic fatty liver disease. Clin. Liver. Dis. 2004, 8, 481-500.

6. Torres, D.M.; Williams, C.D.; Harrison, S.A. Features, diagnosis, and treatment of nonalcoholic fatty liver disease. Clin. Gastroenterol. Hepatol. 2012, 10, 837-858.

7. Day, C.P.; James, O.F. Steatohepatitis: A tale of two "hits"? Gastroenterology 1998, 114, 842-845.

8. Carter-Kent, C.; Zein, N.N.; Feldstein, A.E. Cytokines in the pathogenesis of fatty liver and disease progression to steatohepatitis: Implications for treatment. Am. J. Gastroenterol. 2008, 103, 1036-1042.

9. Browning, J.D.; Horton, J.D. Molecular mediators of hepatic steatosis and liver injury. J. Clin. Invest. 2004, 114, 147-152.

10. Lieber, C.S. CYP2E1: From ASH to NASH. Hepatol. Res. 2004, 28, 1-11.

11. Mannaerts, G.P.; van Veldhoven, P.P.; Casteels, M. Peroxisomal lipid degradation via betaand alpha-oxidation in mammals. Cell Biochem. Biophys. 2000, 32, 73-87.

12. Garcia-Ruiz, C.; Colell, A.; Morales, A.; Kaplowitz, N.; Fernandez-Checa, J.C. Role of oxidative stress generated from the mitochondrial electron transport chain and mitochondrial glutathione status in loss of mitochondrial function and activation of transcription factor nuclear factor-kappa B: Studies with isolated mitochondria and rat hepatocytes. Mol. Pharmacol. 1995, 48, 825-834.

13. Hensley, K.; Kotake, Y.; Sang, H.; Pye, Q.N.; Wallis, G.L.; Kolker, L.M.; Tabatabaie, T.; Stewart, C.A.; Konishi, Y.; Nakae, D.; et al. Dietary choline restriction causes complex I dysfunction and increased $\mathrm{H}(2) \mathrm{O}(2)$ generation in liver mitochondria. Carcinogenesis 2000, 21, 983-989. 
14. Park, H.J.; DiNatale, D.A.; Chung, M.Y.; Park, Y.K.; Lee, J.Y.; Koo, S.I.; O'Connor, M.; Manautou, J.E.; Bruno, R.S. Green tea extracts attenuates hepatic steatosis by decreasing adipose lipogenesis and enhancing hepatic antioxidants defences in ob/ob mice. J. Nutr. Biochem. 2011, 22, 393-400.

15. Shih, C.C.; Shlau, M.T.; Lin, C.H.; Wu, J.B. Momordica charantia ameliorates insulin resistance and dyslipidemia with altered hepatic glucose production and fatty acid synthesis and AMPK phosphorylation in high-fat-fed mice. Phytother. Res. 2014, 28, 363-371.

16. Vidyashankar, S.; Sandeep Varma, R.; Patki, P.S. Quercetin ameliorate insulin resistance and up-regulates cellular antioxidants during oleic acid induced hepatic steatosis in HepG2 cells. Toxicol. In Vitro 2011, 27, 393-400.

17. Kwon, J.H.; Kim, J.H.; Choi, S.E.; Park, K.H.; Lee, M.W. Inhibitory effects of phenolic compounds from needles of Pinus densiflora on nitric oxide and PGE2 production. Arch. Pharm. Res. 2010, 33, 2011-2016.

18. Jung, M.J.; Choi, J.H.; Chung, H.Y.; Jung, J.H.; Choi, J.S. A new C-methylated flavonoid glycoside from Pinus densiflora. Fitoterapia 2001, 72, 943-945.

19. Choi, E.M. Antinociceptive and antiinflammatory activities of pine (Pinus densiflora) pollen extract. Phytother. Res. 2007, 21, 471-475.

20. Ince, I.; Yesil-Celiktas, O.; Karabay-Yavasoglu, N.U.; Elgin, G. Effects of Pinus brutia bark extract and Pycnogenol ${ }^{\circledR}$ in a rat model of carrageenan induced inflammation. Phytomedicine 2009, 16, 1101-1104.

21. Kwak, C.S.; Moon, S.C.; Lee, M.S. Antioxidant, antimutagenic, and antitumor effects of pine needles (Pinus densiflora). Nutr. Cancer 2006, 56, 162-171.

22. Kim, C.S. A comparison study of antibacterial effects of pine needle extractson human skin pathogens. Kor. J. Aesthet Cosmetol. 2012, 10, 25-30.

23. Kim, J.H.; Kang, S.I.; Shin, H.S.; Yoon, S.A.; Kang, S.W.; Ko, H.C.; Kim, S.J. Sasa quelpaertensis and p-coumaric acid attenuate oleic acid-induced lipid accumulation in HepG2 cells. Biosci. Biotechnol. Biochem. 2013, 77, 1595-1598.

24. Li, X.; Wang, R.; Zhou, N.; Wang, X.; Liu, Q.; Bai, Y.; Bai, Y.; Liu, Z.; Yang, H.; Zou, J.; et al. Quercetin improves insulin resistance and hepatic lipid accumulation in vitro in a NAFLD cell model. Biomed. Rep. 2013, 1, 71-76.

25. Rinella, M.E.; Elias, M.S.; Smolak, R.R.; Fu, T.; Borensztajn, J.; Green, R.M. Mechanisms of hepatic steatosis in mice fed a lipogenic methionine choline-deficient diet. J. Lipid Res. 2008, 49, 1068-1076.

26. Cousin, S.P.; Hügl, S.R.; Wrede, C.E.; Kajio, H.; Myers, M.G.; Rhodes, C.J. Free fatty acid-induced inhibition of glucose and insulin-like growth factor I-Induced deoxyribonucleic acid synthesis in the pancreatic beta-Cell Line INS-1. Endocrinology 2001, 142, 229-240.

27. Hwang, Y.J.; Lee, E.J.; Kim, H.R.; Hwang, K.A. NF-кB-targeted anti-inflammatory activity of Prunella vulgaris var. lilacina in macrophages RAW 264.7. Int. J. Mol. Sci. 2013, 14, 21489-21503.

28. Hostanska, K.; Suter, A.; Melzer, J.; Saller, R.; Aller, R. Evaluation of cell death caused by an ethanolic extract of Serenoae repentis fructus $\left(\right.$ Prostasan $^{\circledR}$ ) on human carcinoma cell lines. Anticancer Res. 2007, 27, 873-882. 
29. Fowler, S.D.; Greenspan, P. Application of Nile red, a fluorescent hydrophobic probe, for the detection of neutral lipid deposits in tissue sections: Comparison with oil red O. J. Histochem. Cytochem. 1985, 33, 833-836.

30. Gocze, P.M.; Freeman, D. A factors underlying the variability of lipid droplet fluorescence in MA-10 Leydig tumor cells. Cytometry 1994, 17, 151-158.

31. Schultz, J.R.; Tu, H.; Luk, A.; Repa, J.J.; Medina, J.C.; Li, L.; Schwendner, S.; Wang, S.; Thoolen, M.; Mangelsdorf, D.J.; et al. Role of LXRs in control of lipogenesis. Genes. Dev. 2000, 14, 2831-2838.

32. Feldstein, A.E.; Werneburg, N.W.; Canbay, A.; Guicciardi, M.E.; Bronk, S.F.; Rydzewski, R.; Burgart, L.J.; Gores, G.J. Free fatty acids promote hepatic lipotoxicity by stimulating TNF- $\alpha$ expression via a lysosomal pathway. Hepatology 2004, 40, 185-194.

33. Endo, M.; Masaki, T.; Seike, M.; Yoshimatsu, H. TNF- $\alpha$ induces hepatic steatosis in mice by enhancing gene expression of sterol regulatory element binding protein-1c (SREBP-1c). Exp. Biol. Med. (Maywood) 2007, 232, 614-621.

34. Furukawa, S.; Fujita, T.; Shimabukuro, M.; Iwaki, M.; Yamada, Y.; Nakajima, Y.; Nakayama, O.; Makishima, M.; Matsuda, M.; Shimomura, I. Increased oxidative stress in obesity and its impact on metabolic syndrome. J. Clin. Investig. 2004, 114, 1752-1761.

35. Igata, M.; Motoshima, H.; Tsuruzoe, K.; Kojima, K.; Matsumura, T.; Kondo, T.; Taguchi, T.; Nakamaru, K.; Yano, M.; Kukidome, D.; et al. Adenosine monophosphateactivated protein kinase suppresses vascular smooth muscle cell proliferation through the inhibition of cell cycle progression. Circ. Res. 2005, 97, 837-844.

36. Li, L.; He, Q.; Huang, X.; Man, Y.; Zhou, Y.; Wang, S.; Wang, J.; Li, J. NOX3-derived reactive oxygen species promote TNF- $\alpha$-induced reductions in hepatocyte glycogen levels via a JNK pathway. FEBS Lett. 2010, 584, 995-1000.

37. Koek, G.H.; Liedorp, P.R.; Bast, A. The role of oxidative stress in non-alcoholic steatohepatitis. Clin. Chim. Acta 2011, 412, 1297-1305.

38. Paschos, P.; Paletas, K. Non alcoholic fatty liver disease and metabolic syndrome. Hippokratia 2009, 13, 9-19.

39. Mavrogiannaki, A.N.; Migdalis, I.N. Nonalcoholic fatty liver disease, diabetes mellitus and cardiovascular disease: Newer Data. Int. J. Endocrinol. 2013, 2013, 450-639.

40. Ibrahim, M.A.; Kelleni, M.; Geddawy, A. Nonalcoholic fatty liver disease: Current and potential therapies. Life Sci. 2013, 92, 114-118.

41. Del Prete, A.; Scalera, A.; Iadevaia, M.D.; Miranda, A.; Zulli, C.; Gaeta, L.; Tuccillo, C.; Federico, A.; Loguercio, C. Herbal products: Benefits, limits, and applications in chronic liver disease. Evid. Based Complement. Alternat. Med. 2012, 2012, 837939, doi:10.1155/2012/837939.

42. Pferschy-Wenzig, E.M.; Atanasov, A.G.; Malainer, C.; Noha, S.M.; Kunert, O.; Schuster, D.; Heiss, E.H.; Oberlies, N.H.; Wagner, H.; Bauer, R.; et al. Identification of isosilybin a from milk thistle seeds as an agonist of peroxisome proliferator-activated receptor gamma. J. Nat. Prod. 2014, 77, 842-847.

43. Peng, C.H.; Liu, L.K.; Chuang, C.M.; Chyau, C.C.; Huang, C.N.; Wang, C.J. Mulberry water extracts possess an anti-obesity effect and ability to inhibit hepatic lipogenesis and promote lipolysis. J. Agric. Food Chem. 2011, 59, 2663-2671. 
44. Laurent, T.; Okuda, Y.; Chijimatsu, T.; Umeki, M.; Kobayashi, S.; Kataoka, Y.; Tatsuguchi, I.; Mochizuki, S.; Oda, H. Freshwater clam extract ameliorates triglyceride and cholesterol metabolism through the expression of genes involved in hepatic lipogenesis and cholesterol degradation in rats. Evid. Based Complement. Alternat. Med. 2013, 2013, 830684, doi:10.1155/2013/830684.

45. Shimano, H.; Yahagi, N.; Amemiya-kudo, M.; Hasty, A.H.; Osuga, J.; Tamura, Y.; Shionoiri, F.; Iizuka, Y.; Ohashi, K.; Harada, K.; et al. Sterol regulatory element-binding protein-1 as a key transcription factor for nutritional induction of lipogenic enzyme genes. J. Biol. Chem. 1999, 50, 35832-35839.

46. Menendez, J.A.; Lupu, R. Fatty acid synthase-catalyzed de novo fatty acid biosynthesis: From anabolic-energy-storage pathway in normal tissues to jack-of-all-trades in cancer cells. Arch. Immunol. Ther. Exp. (Warsz) 2004, 52, 414-426.

47. Schimmack, G.; Defronzo, R.A.; Musi, N. AMP-activated protein kinase: Role in metabolism and therapeutic implications. Diabetes Obes. Metab. 2006, 8, 591-602.

48. Zhou, G.; Myers, R.; Li, Y. Role of AMP-activated protein kinase in mechanism of metformin action. J. Clin. Investig. 2001, 108, 1167-1174.

49. McGarry, J.D.; Brown, N.F. The mitochondrial carnitine palmitoyltransferase system. From concept to molecularanalysis. Eur. J. Biochem. 1997. 244, 1-14.

50. Wakil, S.J.; Abu-Elheiga, L.A. Fatty acid metabolism: Target for metabolic syndrome. J. Lipid Res. 2009, 50, S138-S143.

51. Wong, V.W.; Hui, A.Y.; Tsang, S.W.; Chan, J.L.; Tse, A.M.; Chan, K.F.; So, W.Y.; Cheng, A.Y.; Ng, W.F.; Wong, G.L.; et al. Metabolic and adipokine profile of Chinese patients with nonalcoholic fatty liver disease. Clin. Gastroenterol. Hepatol. 2006, 4, 1154-1161.

52. Bahcecioglu, I.H.; Yalniz, M.; Ataseven, H.; Ilhan, N.; Ozercan, I.H.; Seckin, D.; Sahin, K. Levels of serum hyaluronic acid, TNF- $\alpha$ and IL-8 in patients with nonalcoholic steatohepatitis. Hepatogastroenterology 2005, 52, 1549-1553.

53. Cui, W.; Chen, S.L.; Hu, K.Q. Quantification and mechanisms of oleic acid-induced steatosis in HepG2 cells. Am. J. Transl. Res. 2010, 2, 95-104.

54. Crespo, J.; Cayon, A.; Fernandez-Gil, P.; Hernández-Guerra, M.; Mayorga, M.; Domínguez-Díez, A.; Fernández-Escalante, J.C.; Pons-Romero, F. Gene expression of tumor necrosis factor alpha and TNF-receptors, p55 and p75, in nonalcoholic steatohepatitis patients. Hepatology 2001, 34, 1158-1163.

55. Francés, D.E.; Ingaramo, P.I.; Ronco, M.T.; Carnovale, C.E. Diabetes, an inflammatory process: Oxidative Stress and TNF- $\alpha$ involved in hepatic complication. J. Biomed. Sci. Eng. 2013, 6, 645-653.

56. Jung, M.J.; Chung, H.Y.; Choi, J.H.; Choi, J.S. Antioxidant principles from the needles of red pine, Pinus densiflora. Phytother. Res. 2003, 17, 1064-1068.

(C)2014 by the authors; licensee MDPI, Basel, Switzerland. This article is an open access article distributed under the terms and conditions of the Creative Commons Attribution license (http://creativecommons.org/licenses/by/3.0/). 